\title{
Accuracy of Reflectorless Technology for Distance Measurements in Practice
}

\author{
Žarko NESTOROVIĆ*, Miroslav KUBURIĆ, Milan TRIFKOVIĆ, Milan KEKANOVIĆ
}

\begin{abstract}
Utilization of reflectorless technology for distance measurements is very useful in surveying practice and improves efficiency of geodetic measurements. Some experience, however, has shown that measurements of distance by utilization of reflectorless technology could differ more than expected. In this research, the main aim was to find out if the accuracy and reliability of measured distances by reflectorless technology are on the acceptable level for determination position of the points i.e. their coordinates. Common characteristic of investigated accuracy of distances obtained by reflectorless technology in literature is careful design of experiments and controlled conditions, but in practice it is not the case. That is the reason for designing the experiment, which reflects the conditions as near as possible to the real conditions in practice. The surfaces for measurement were divided into two groups: regular and irregular and differences of distances obtained by reflectorless measurements were investigated in the case of manual and automated sighting. Obtained results show that distances, when measured by using reflectorless technology in only one position of telescope, could not be reliable while the average value of measurements obtained in two positions of telescope are of higher accuracy especially for the longer distances.
\end{abstract}

Keywords: distance accuracy; reflectorless; repeated measurements

\section{INTRODUCTION}

Some experiences in distance measurements have shown that utilization of reflectorless mode in two positions of telescope resulted in differences greater than expected. The accuracy of reflectorless distance measurement is declared mainly with $\sigma_{d}=2+2 \mathrm{ppm}[1,2]$, or $\sigma_{d}=3+2 \mathrm{ppm}$ [3] but results obtained in practice exceeded these values significantly. This fact inspired the idea for researching the phenomenon of distance differences obtained in two positions of total stations' telescope by reflectorless technology. The practical importance of this research stems from the fact the utilization of reflectorless mode of distance measurements is very useful in engineering measurements and its reliability might be crucial for efficiency in solving certain engineering problems.

The accuracy and reliability of reflectorless distances measurement were the issue of numerous researches because of its importance for efficiency in solving geodetic tasks. In paper [4] the accuracy of long-range reflectorless distance measurement was evaluated depending on materials of targets, target size and different incidence angles. Obtained results showed the maximum differences for concrete at incidence angle of $60^{\circ}$ in the range from -15 $\mathrm{mm}$ to $+1 \mathrm{~mm}$, and differences increase with length of measured distances (the range of measured distances were from $100 \mathrm{~m}$ to $600 \mathrm{~m}$ ). In paper [5] the accuracy of reflectorless measurements dependence on reflectance of targets was tested. Despite the conclusion that reflectance did not affect the accuracy significantly some limitations of technology suggest that each specific case requires testing accuracy of reflectorless distance measurements.

The concepts of precision, accuracy and reliability might be also suitable for estimating the quality of reflectorless measurements of distances. The accuracy could be defined as the degree of closeness of an observation to the "true" value while the precision is defined as the degree of closeness and consistency of repeated measurements of the same quantity to each other [6]. The concept of reliability in geodesy is connected with geodetic networks, i.e. with the influence of undetected outliers on the model (external reliability) and with maximum undetectable error in the model [7]. The accuracy, precision and reliability with respect of the different errors were researched and conclusion was that "there remains a number of questions in regard of specific variables" [8].

Research of different surfaces made from different materials and painted with different colour influences resulted with significantly less value of accuracy than specified for used instrument [9]. The evaluation of reflectorless total station accuracy leads to conclusion that reflectorless and prismatic options converge for the short distances (up to $35 \mathrm{~m}$ ) and for the longer distances the prismatic option is of better accuracy than reflectorless option [10] for used total station. Also, this research showed that increasing inclining angle leads to increase of distance measurement error. Research for the accuracy of distances measured by reflectorless technology in the range of $50 \mathrm{~m}$ resulted by conclusion that correct measurement fluctuates between $20 \%$ and $85 \%$, which means that reflectorless technology needs improvement [11]. The long-range reflectorless distance (up to $1000 \mathrm{~m}$ ) measurements show that the accuracy is dependent on the incidence angle and that the size of target shall increase with distance [12]. Also the specified accuracy for long mode decreases at the value of $10 \mathrm{~mm}+10 \mathrm{ppm}$. In order to investigate the performance of reflectorless total stations the researchers [13] carefully established geodetic test line. Common characteristic for all quoted research is the carefully controlled conditions for reflectorless measurements of distances. In practice however the surveyors could not control the conditions and the results of distance measurements obtained by reflectorless technology are rarely possible to be checked. This problem indicates that obtained result of distance measurement should be reliable and obtained in efficient manner which means that measurement in one position of total station's telescope should be accurate in the range of declared accuracy for used total station. Also in practice the type of surface, distance and incidence angle could not be chosen by the researchers' free will which means that the measurements should be performed with the limits defined by site. 
In this paper the concept of measurement reliability is used in the sense of the trust which we could have in the obtained measurements i.e. should the reflectorless measurements be trusted without repetition.

The experiment for this research was designed to check the real conditions on the site and encompassed distance measurements on two different kinds of surfaces and with two different kinds of sighting. The surfaces are defined as regular and irregular while the sighting was completely manual and automated. Regular surface is defined as a surface with known roughness and irregular surface is defined as surface with unknown roughness. Regular surface is obtained by targets printed on the paper (A4 dimension) while for the irregular surface the cross written on the concrete surface was utilized. The manual sighting means that complete measurements were provided by sighting with manual corrections while automated sighting means that only in first position of telescope sighting was provided manually but in further measurements the results were only recorded in the position reached by total stations. All measurements were provided in two sets of angles.

The obtained results of measured distances were analysed in two ways: internal analysis which encompassed differences obtained for the same distance measured in different positions of telescope in two sets of measurements and external analysis which encompassed differences between obtained results of distances and their "true" values. "True" values of distances were obtained from adjusted coordinates in geodetic network.

The main aim of research was to test the accordance of distances as follows (both for types of sighting and types of surfaces):

- Equality of distances obtained by adjustment of manual and automated sighting (two sets of data for the same network of points);

- Equality of distances obtained in two sets of measurements (equality of their averages in two positions of telescope);

- Equality of distances obtained by manual and automated sighting and

- Equality of distances obtained by reflectorless measurements and their "true" values obtained from adjustment.

The equality of distances was determined by utilization of common statistical methods [14].

\section{MATERIALS AND METHODS}

The data of this experiment were obtained through measurement of directions, zenith angles and distances in two sets of measurements in the network designed for testing quality of reflectorless distance measurements. Three massive concrete pillars were adopted for measurements with prisms and six free stations were utilized for measurements on targets with reflectorless technology. The targets were aligned in almost straight line on the distance of approximately $200 \mathrm{~m}$.

On each free station the two sets of measurements were provided: measurements with manual sighting and the measurements with automated sighting. Each of these measurements (with manual and automated sighting) was provided in two sets of measurements. The analysis is provided in four possible combinations as given by Fig. 1.

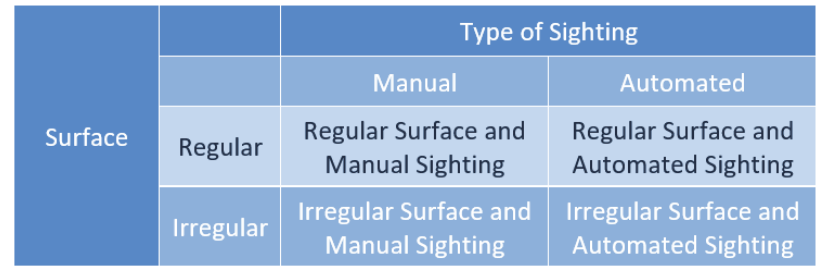

Figure 1 Combinations of data analysis

The "true" values of distances were obtained through adjustment by using least square model:

$l=A x$

$[p v v]=\min$

$\left[x^{\mathrm{T}} x\right]=\min$

The "true" values of distances measured by reflectorless mode were determined by utilization of distances measured on prisms mounted on pillars and horizontal directions.

The differences were obtained by the formulae:

$\Delta_{i}=D_{i j}^{T}-D_{i j}$

$\Delta_{i}^{T}=D_{i j}^{T}-\bar{D}_{i j}$

where: $\Delta_{i}$ - difference between "true" value of distance and results obtained by reflectorless measurement for each value in two sets; $\Delta_{i}^{T}$ - difference between "true" value of distance and average reflectorless measurement for all values in two sets; $D_{i j}^{T}$ - "true" value of distance determined from adjusted coordinates; $D_{i j}$ - each value of distance measured by reflectorless and $\bar{D}_{i j}$ - average value of measured distance by using reflectorless mode.

The statistical tests were provided by utilization of Student's distribution:

$t=\frac{d}{m_{d}} \sim t_{f, \alpha}$

where: $t$ - Student's statistics; $d$ - difference between tested distances; $m_{d}$ - mean squared error of difference $d$ and $t_{f, \alpha}$ - quantile of Student's distribution for degree of freedom $f$ and level of significance $\alpha$ (in this analysis is adopted $\alpha=0.005$ ).

The mean squared error for distances obtained from adjusted coordinates is calculated by the following formula:

$m_{D_{i j}^{T}}=m_{0} \sqrt{g^{T} \boldsymbol{Q}_{x} \boldsymbol{g}}$ 
where: $m_{D_{i j}^{T}}$ - means squared error of distance determined by adjustment; $m_{0}$ - mean squared error of adjustment; $\boldsymbol{g}$ - vector of factors and $\boldsymbol{Q}_{\boldsymbol{x}}$ - cofactor matrix.

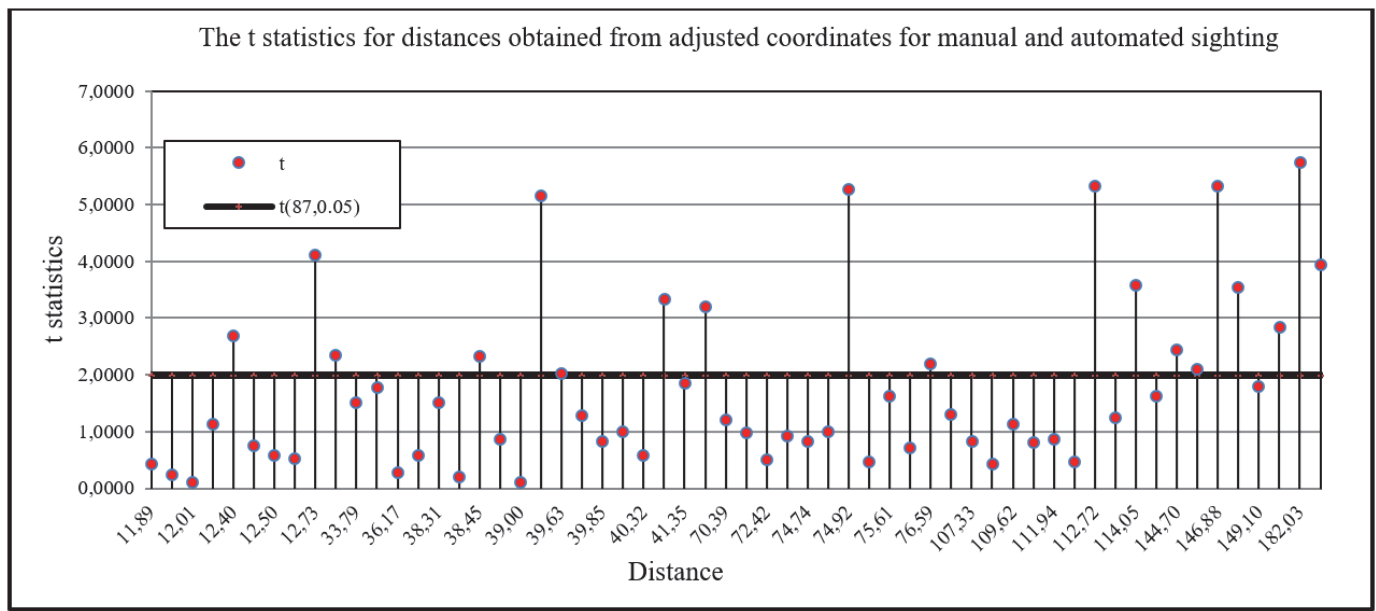

Figure $2 \mathrm{t}$ statistics for distances obtained from adjusted coordinates for manual and automated sighting
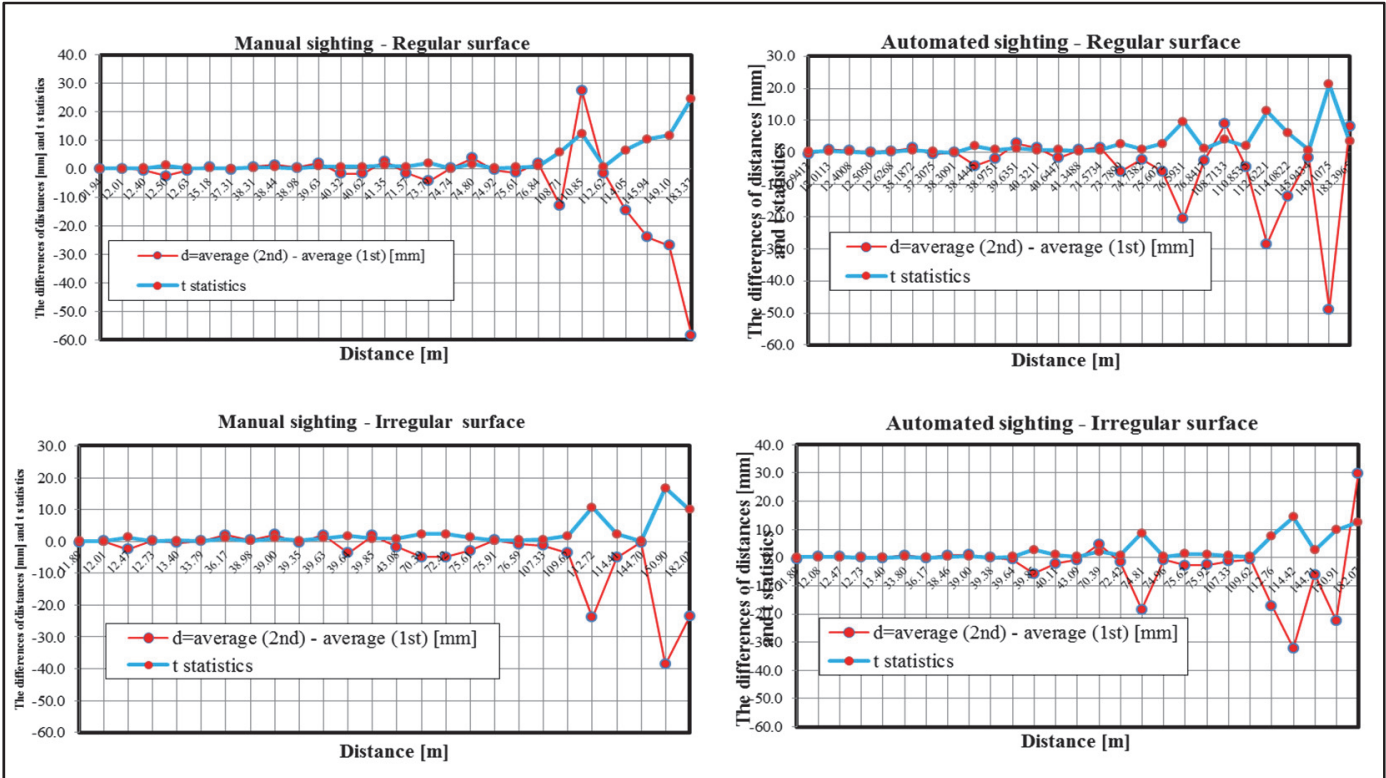

Figure 3 The differences of distances measured by reflectorless and their "true" values

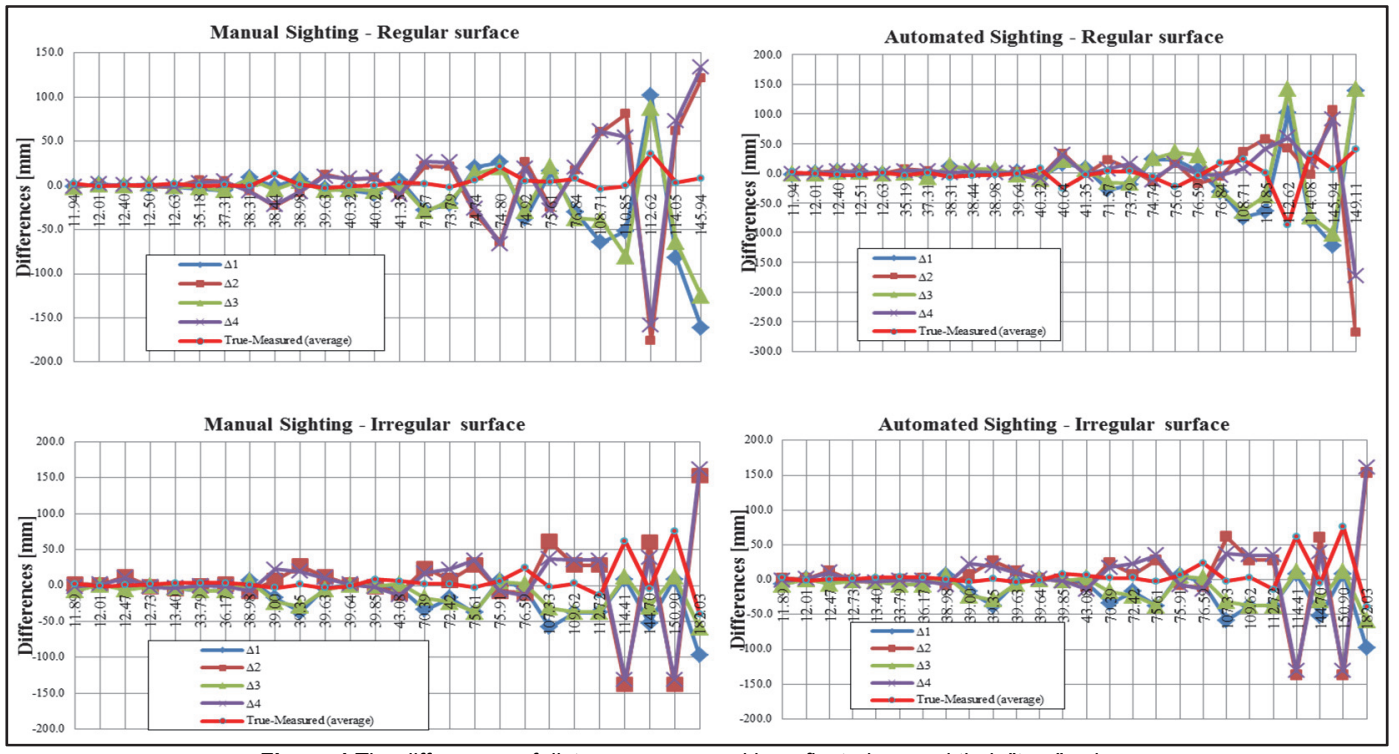

Figure 4 The differences of distances measured by reflectorless and their "true" values 


\section{RESULTS AND DISSCUSSION}

The results are shown in the following order: - Equality of adjusted distances without reflectorless measurements from results obtained by manual and automated sighting (Fig. 2). The obtained results showed that automated sighting produced the differences in $33 \%$ cases (19 adopted alternative hypotheses vs. 39 adopted hypotheses);

- Equality of reflectorless measured distances between averages in the $2^{\text {nd }}$ and $1^{\text {st }}$ set (Fig. 3). The obtained results showed that acceptance of null hypothesis varies from $63 \%$ to $75 \%$ (acceptance of alternative hypothesis varies from $25 \%$ to $37 \%)$;

- Equality of differences between distances measured by reflectorless and their "true" values as well as differences between themselves (Fig. 4). The obtained results showed that acceptance of null hypothesis varies from $58 \%$ to $78 \%$ (acceptance of alternative hypothesis varies from 22\% to $42 \%)$.

The acceptance of null hypotheses (equality of measured distances by reflectorless technology between averages in $1^{\text {st }}$ and $2^{\text {nd }}$ set) for manual and automated sighting (both for regular and irregular surface) is shown in Tab. 1, while the acceptance of null hypotheses (equality of measured distances by reflectorless technology between average in two sets and their "true" value) for manual and automated sighting (both for regular and irregular surface) is shown in Tab. 2. For the purpose of this analysis, $\sigma_{d}=2$ +2 ppm is adopted (which is in accordance with the used total station in this research) for the measured distance with reflectorless technology and $m_{D_{i j}^{T}}$ was obtained from adjustment.
Table 1 The acceptance of null hypotheses for differences of average distances between two sets

\begin{tabular}{|c|c|c|c|}
\hline \multicolumn{2}{|c|}{} & \multicolumn{2}{c|}{ Sighting } \\
\cline { 3 - 4 } \multicolumn{2}{|c|}{} & Manual & Automated \\
\hline \multirow{2}{*}{ Surface } & Regular & $75 \%$ & $63 \%$ \\
\cline { 2 - 4 } & Irregular & $73 \%$ & $70 \%$ \\
\hline
\end{tabular}

Table 2 The acceptance of null hypotheses for differences of average distances and their "true" values

\begin{tabular}{|c|c|c|c|}
\hline \multicolumn{2}{|c|}{} & \multicolumn{2}{|c|}{ Sighting } \\
\cline { 3 - 4 } \multicolumn{2}{|c|}{} & Manual & Automated \\
\hline \multirow{2}{*}{ Surface } & Regular & $78 \%$ & $66 \%$ \\
\cline { 2 - 4 } & Irregular & $73 \%$ & $58 \%$ \\
\hline
\end{tabular}

According to obtained results it is obvious that automated sighting resulted by lower level of null hypothesis acceptance than manual sighting both for regular and irregular surfaces. Also the automated sighting resulted by lower level of null hypothesis acceptance than manual sighting both for differences of distance averages between two sets of reflectorless measurements and for differences between overall average of reflectorless measured distances and their true values. The analysis showed that the differences increase with the increasing of distances.

The relation between distance and incidence angle $\beta$ and distance is given by the following formula:

$\beta=\arcsin \frac{h}{D}$

where: $h$ - distance from free station to the line of targets and $D$ - horizontal distance from free station to target.

The dependence of differences between measured distances by reflectorless technology and their "true" values are shown in Fig. 5 for the case of manual sighting and in Fig. 6 for the case of automated sighting.
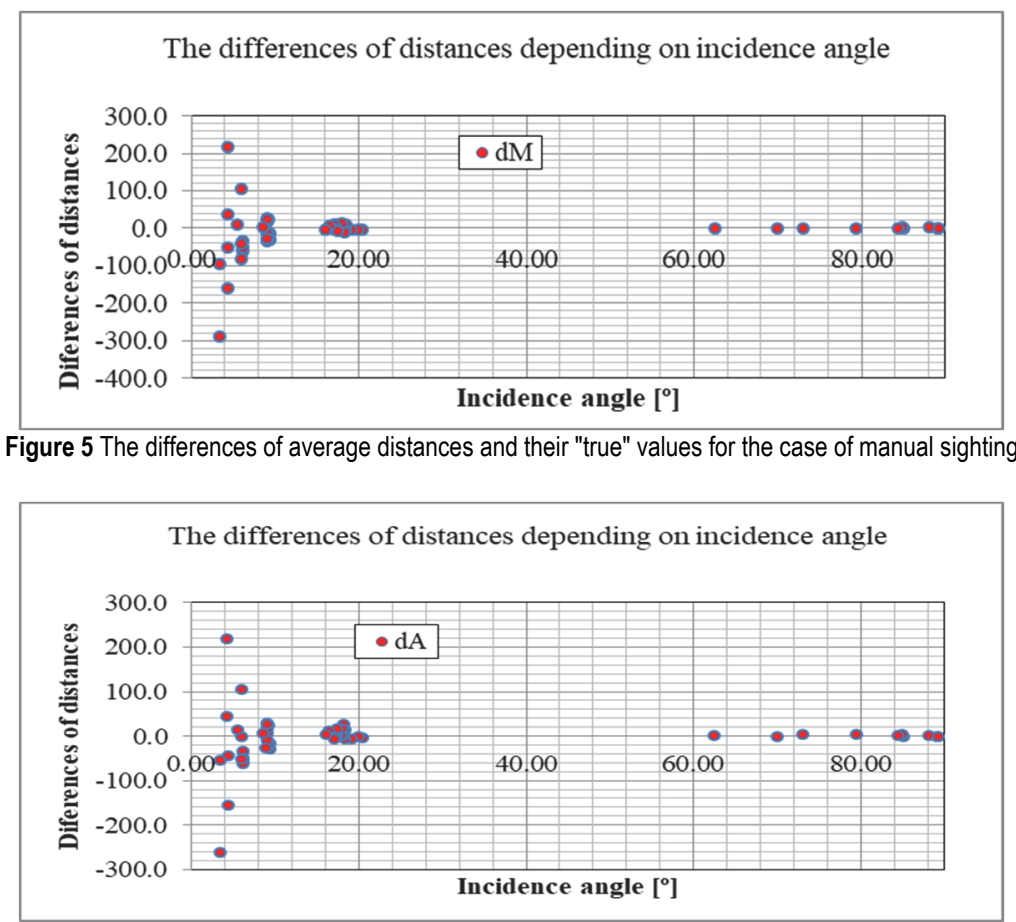

Figure 6 The differences of average distances and their "true" values for the case of automated sighting

Considering the dependency of differences between distances measured by reflectorless technology and their 
"true" values it is obvious that for incidence angles smaller than $20^{\circ}$ they vary significantly and in unpredictable manner.

\section{CONCLUSION}

According to obtained results and for conditions (surfaces, instrument and type of sighting) utilized in current experiment it is possible to conclude that for the utilization of reflectorless technology it is necessary to provide measurements at least in two positions of telescope especially if incidence angle is smaller than $20^{\circ}$. The differences could vary in unpredictable manner and could take the values greater than expected, regardless of regularity of surface and type of sighting. Only in cases when the distances are small it is possible to obtain acceptable results even in case of incidence angles smaller than $20^{\circ}$ but also if they were measured in, at least, two sets of angles. The reliability of repeated measurement of distances by reflectorless technology increases with number of measurements but must be used very carefully in real conditions with considering type of surface, distance and incidence angles.

\section{REFERENCES}

[1] https://w3.leicageosystems.com/downloads123/zz/tps/t s30/brochures-datasheet/ts30 technical data en.pdf, last accessed 2020/01/15

[2] https://www.topcon.co.jp/en/positioning/sokkia/produc ts/pdf/iM-50 E.pdf, last accessed 2020/01/15

[3] https://www.topcon.co.jp/en/positioning/products/pdf/ ES E.pdf, last accessed 2020/01/15

[4] Khalil, R. (2015). Accuracy evaluation of long-range reflectorless distance measurement. Positioning, 6(03), 61 . https://doi.org/10.4236/pos.2015.63007

[5] Mazalová, J., Valentová, K., \& Vlčková, L. (2010). Testing of accuracy of reflectorless distance measurement of selected Leica and Topcon total stations.

[6] Staudinger, M. (2000). A cost oriented approach to geodetic network optimisation. Institute for Geoinformation, Vienna University of Technology.

[7] Kavouras, M. (1985). On the detection of outliers and the determination of reliability in geodetic networks. University of New Brunswick.

[8] Coaker, L. H. (2009). Reflector-less total station measurements and their accuracy, precision and reliability. $1-82$.

[9] Beshr, A. A. A. \& Islam, M. (2011). Abo Elnaga. Investigating the accuracy of digital levels and reflectorless total stations for purposes of geodetic engineering. Alexandria Engineering Journal, 50(4), 399-405. https://doi.org/10.1016/j.aej.2011.12.004

[10] Fawzy, H. E. D. (2015). Evaluate the accuracy of reflectorless total station. International Journal of Civil Engineering and Technology, 6(3), 23-30.

[11] Lambrou, E. \& Pantazis, G. (2010). Evaluation of the credibility of reflectorless distance measurement. Journal of surveying engineering, 136(4), 165-171. https://doi.org/10.1061/(ASCE)SU.1943-5428.0000029

[12] Khalil, R. (2015). Accuracy evaluation of long-range reflectorless distance measurement. Positioning, 6(03), 61.

[13] Alsalman, A. S., Ali, E. A, Abanmy, F. A., \& Ibrahim, E. E. A (2010). Appraising Reflectorless Total Station Instruments. Journal of King Saud University-Engineering Sciences, 22(1), 1-8.

https://doi.org/10.1016/S1018-3639(18)30504-X
[14] Perovic, G. (2005). Least squares. Monograph, University of Belgrade, Faculty of Civil Engineering, Belgrade.

\section{Contact information}

Žarko NESTOROVIĆ, M.sc of geodesy

(Corresponding author)

Public electric company "Elektroprivreda Srbije", Belgrade, Serbia,

19320 Kladovo, Serbia

E-mail: nzarko07@gmail.com

Miroslav KUBURIĆ, Associate professor

Faculty of Civil Engineering Subotica,

University of Novi Sad,

Kozaračka 2a, 24000 Subotica, Serbia

E-mail: mkuburic@gf.uns.ac.rs

Milan TRIFKOVIĆ, Full time professor

Faculty of Civil Engineering Subotica,

University of Novi Sad,

Kozaračka 2a, 24000 Subotica, Serbia

E-mail: milantri@eunet.rs

Milan KEKANOVIĆ, Associate professor

Faculty of Civil Engineering Subotica,

University of Novi Sad,

Kozaračka 2a, 24000 Subotica, Serbia

E-mail: kekec@gf.uns.ac.rs 